\title{
Cardiopulmonary Resuscitation Knowledge and Experience Among Dentists in Turkey
}

\section{(1) Ömer Ekici}

Department of Oral and Maxillofacial Surgery, Afyonkarahisar Health Sciences University, Faculty of Dentistry, Afyonkarahisar, Turkey

\begin{abstract}
Aim: Cardiopulmonary resuscitation (CPR) is an essential skill that all health care professionals are advised to acquire. Dentists, as health professionals, should be able to recognize cardiac arrest and effectively perform CPR. This study aimed to evaluate the knowledge and experiences of general dentists in Turkey on CPR.

Materials and Methods: A cross-sectional study was conducted among 152 general dentists working in Turkey. Data were obtained through an electronic survey including the knowledge and attitude of dentists on CPR based on the 2015 American Heart Association guidelines update. Data were evaluated using the statistical package for social sciences (SPSS version 22).

Results: A total of 152 general dentists participated in the present study, giving a response rate of $76 \%$. While $44 \%$ of the dentists answered more than half of the questions, none of the dentists answered all the questions correctly. Although only $1.3 \%$ of the dentists stated that they had encountered a cardiac arrest case, $34.2 \%$ of them stated that they could evaluate a cardiac arrest case. In addition, although $73.7 \%$ of the dentists had previously received cardiopulmonary resuscitation training, only $6.6 \%$ of them considered themselves adequate in CPR administration. Of the dentists, $11.8 \%$ were aware of the 2015 CPR guidelines. Among the dentists, $88.2 \%$ of them stated that they should be skilled in CPR as a dentist, while $90.8 \%$ of them wanted to undergo CPR training.

Conclusion: This study showed that the majority of general dentists in Turkey had insufficient knowledge on CPR. Therefore, CPR training should be regularly provided to general dentists in the country.

Keywords: Cardiopulmonary resuscitation, basic life support, medical emergencies, dentistry
\end{abstract}

\section{Introduction}

Heart disease is one of the most common diseases in the world, resulting in high morbidity and high cost to health. Cardiac arrest is a common cause of death in developed countries (1). According to the American Heart Association (AHA), cardiac arrest is described as "discontinuation of cardiac mechanical activity, verified by lack of measurable pulse, apnea, and loss of awareness" (2). The heart's resistance to anoxia is fairly strong however if the anoxia persists more than 3 or 4 minutes, the central nervous system may show permanent lesions. Cardiopulmonary resuscitation (CPR) is the provision of blood and oxygen to these organs to satisfy the metabolic needs of the myocardium and brain when sudden cardiac arrest occurs due to reversible reasons. CPR is an emergency procedure that aims to restore spontaneous circulation by performing compressions of the chest with or without ventilation (3). According to the AHA, CPR is a component of the "chain of survival". The chain is a series of actions that help provide a person with a heart attack the highest chance of survival (4).

The success of CPR depends on how quickly the scene of an accident can be reached and how effective CPR can be performed. Recent studies on the efficacy of CPR have shown that the best way to achieve resuscitation in cardiac arrest is high-quality CPR with minimal interruptions and early defibrillation (5). Guidelines for CPR are updated by AHA and the European Resuscitation Council in various time frames. Although there are some differences in resuscitation practices, each guide emphasizes the importance of early diagnosis and rapid intervention. Patients resuscitated 
immediately after cardiac arrest have a two to three-fold higher survival rate (patients who did not receive CPR were $2.5 \%$ and those receiving 8.2\%) (6). Furthermore, if CPR does not start immediately after cardiac arrest, the survival rate would be decreased by $7-10 \%$ per minute after initiation of an event (7).

Although the incidence of medical emergencies in dentistry is rare, there may be emergency conditions for the patient, staff, or even the patient attendant (8). The most important medical emergency for a dentist is a cardiopulmonary arrest (CPA), so a diagnosis and treatment should be made as soon as possible. Although unusual, there are reports of CPA-related death in dentistry during dental treatment (9-10). In most patients with CPA, the only way to save lives is to immediately initiate CPR. Approximately $92 \%$ of out-of-hospital cardiac arrest cases die due to the absence of emergency CPR (4). Therefore, as a health professional, dentists should be able to recognize CPA and perform CPR. CPR, including the use of an automated external defibrillator, is one of the basic skills necessary for the management of emergencies in dentistry. There are not enough studies that have evaluated the dentists' knowledge and skills to perform CPR in Turkey. The aim of this study was to evaluate the knowledge and skill levels of dentists related to CPR.

\section{Materials and Methods}

This cross-sectional survey was carried out from January 2019 to September 2019 in Turkey. General dental practitioners who work in the ministry of health and private dental offices were included in this study. This study was approved by the Ethical Committee of the Faculty of Medicine, Afyonkarahisar Health Sciences University (no: 2019/10-316, date: 04.10.2019), and was performed in full compliance with the Helsinki Declaration of the World Medical Association.

The structured questionnaire consisting of 29 questions was prepared by the author for use in the study. Four of the questions were related to demographic data while the other 25 questions were related to CPR knowledge and experience of dentists. In this study, the knowledge of dentists was evaluated according to the CPR guidelines, which was last updated in 2015. The validity and reliability of the questions were confirmed with the pre-test method by a pilot group of 25 dentists. The questionnaire sent to dentists working in various hospitals in Turkey via e-mail.

\section{Statistical Analysis}

Survey data were analyzed using the Statistical Package for Social Sciences (SPSS-22). Descriptive statistics have been provided using the number, percentage. For questions measuring levels of knowledge, the participants were given "1 point" for each correct answer and "0 points" for each wrong answer. In the total score,
0-4 points were evaluated as an insufficient level of knowledge and 5-10 points as sufficient level of knowledge. Pearson chisquare test was used to determine the score differences between the groups. The mean difference was considered significant at 0.05 level.

\section{Results}

One hundred and fifty-two valid questionnaires were attained from dentists (response rate of $76 \%$ ). The demographic characteristics of the participants were given in Table 1. It was seen in this table that half of the participants were between the ages of $25-34,56.6 \%$ were women and $68.4 \%$ were married. The majority of the participants (42.1\%) had a working experienced period of 1-5 years and most participants (43.4\%) had worked under the Ministry of Health.

Table 2 was summarized the respondent dentists' knowledge of CPR. The first two questions concerned opening the airway method. While the dentist who correctly answered the maneuver applied in patients without a cervical injury is $71.2 \%$, it decreased to $25 \%$ in patients with a cervical injury. Half of the dentists correctly answered the duration of the assessment of the casualty. $69.7 \%$ of the dentists correctly answered how to apply rescue breathing in infants, while $1.3 \%$ correctly answered to the location of cardiac massage in infants and adults. $13.2 \%$ of the dentists answered the "ventilation rate", $27.6 \%$ of the "rate of chest compression", $64.5 \%$ of the "depth of chest compression",

\begin{tabular}{|l|l|l|l|}
\hline \multicolumn{4}{|l}{ Table 1. Demographic characteristics of the participants } \\
\hline \multirow{3}{*}{ Gender } & Female & Number, $n$ & Percentage, \% \\
\cline { 2 - 4 } & Male & 86 & 56.6 \\
\hline \multirow{4}{*}{ Age groups } & $<25$ & 66 & 43.4 \\
\cline { 2 - 4 } & $25-34$ & 12 & 7.9 \\
\cline { 2 - 4 } & $35-44$ & 76 & 50 \\
\cline { 2 - 4 } & 45 and over & 8 & 36.8 \\
\hline \multirow{3}{*}{ Marital status } & Married & 104 & 5.3 \\
\cline { 2 - 4 } & Single & 48 & 68.4 \\
\hline \multirow{4}{*}{ Working } & $1-5$ years & 64 & 42.1 \\
\cline { 2 - 4 } & $6-10$ years & 28 & 18.4 \\
\cline { 2 - 4 } & $11-15$ years & 36 & 23.7 \\
\cline { 2 - 4 } & $15-20$ years & 20 & 13.2 \\
\cline { 2 - 4 } & 20 years and more & 4 & 2.6 \\
\hline \multirow{4}{*}{ Working places } & Ministry of Health & 66 & 43.4 \\
\cline { 2 - 4 } & University & 32 & 21.1 \\
\cline { 2 - 4 } & Private sector & 54 & 35.5 \\
\hline n: Number & & & \\
\hline
\end{tabular}


$42.1 \%$ of the "compression/ventilation ratio" was answered correctly. The number of people who know the drug and dose that should be applied to the patient during a cardiac arrest was $51.3 \%$.

Figure 1 showed the percentage distribution of the participant scores. Accordingly, there were no participants who answered all questions correctly (10 points). The percentage of participants who got 7 and 8 points was only $5.3 \% .26 .3 \%$ of the participants answered half of the questions correctly. While $10.5 \%$ of the participants could answer only one question, $7.9 \%$ had been answered two questions. While the knowledge level of $44.7 \%$ of dentists about CPR was "sufficient (5-10 point)", 55.3\% of the dentists were found to be "insufficient (0-4 point)" in this study.

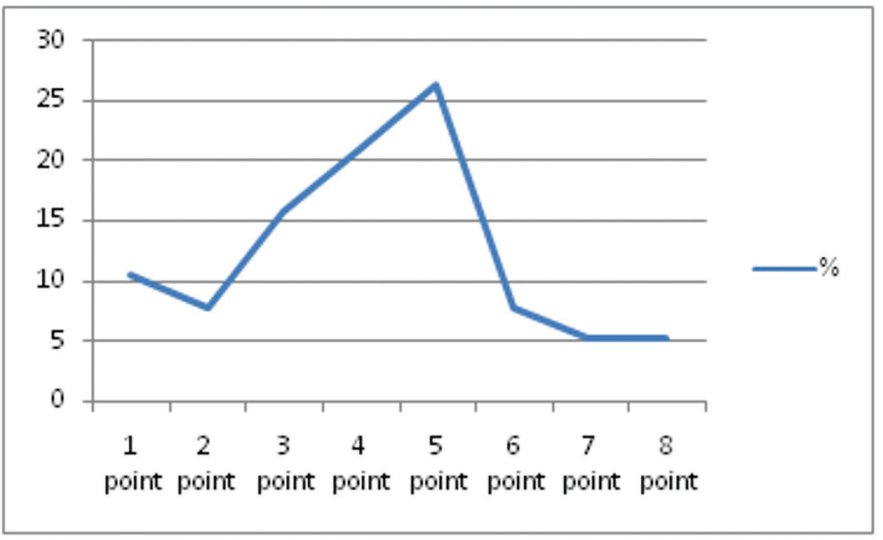

Figure 1. Distribution of participant points (\%)

Dentists' skills and experiences related to CPR were given Table 3. While $1.3 \%$ of dentists stated that they had encountered cardiac arrest, 34.2\% stated that they could evaluate the cardiac arrest case. In an emergency, 30.3\% of dentists stated that they could place an oro-pharyngeal airway, $35.5 \%$ could ventilate with a balloon-mask and $25 \%$ could perform vascular access and IV drug implementation. Half of the dentists stated that they had applied CPR on mannequins, 5.3\% had applied CPR on the patient. 10.5\% of dentists knew how to use an automatic external defibrillator. $73.7 \%$ of dentists previously had received CPR training, only $6.6 \%$ of them considered themselves adequate for CPR administration. $11.8 \%$ of the dentist was knowledgeable about the 2015 CPR guideline.

88.2\% of dentists stated that they should know CPR as a dentist. 90.8\% of dentists stated to want to get CPR training. $86.8 \%$ of the dentists stated that they could face legal problems due to CPR application as a dentist. $42.1 \%$ of the dentists stated that they could avoid applying CPR because of the possibility of legal problems. In the study, whether there was a difference in theoretical knowledge level between those who received CPR training and those who did not were compared with Pearson's chi-square test t-test. While the average scores of those who stated that they had received CPR training before were 4.16, the average scores of those who did not receive CPR were found to be 4.15. Accordingly, there was no significant difference between the two groups $(p=1.98132)$.

\section{Discussion}

This is the first study in Turkey to assess the knowledge and experience of CPR among dentists, to the best of our knowledge. In this study, it can be said that $44 \%$ of the participants had a theoretical level of knowledge because they answered more than half of the questions. Similar results (46\%, 37\%, 36\%) were found by Gonzaga et al. (10) Kavari and Choedri (11) and Alkandari et al. (12) for Brazilian, Iranian, and Kuwaiti dentists respectively. Jamalpour et al. (13) reported that nearly $39 \%$ of Iranian dentists were not able to answer any question correctly and nearly only $4 \%$ were able to perform CPR properly on the manikin. In the present study, while $10.5 \%$ of the participants could answer only one question, $7.9 \%$ could answer two questions. These findings of the study are in line with other studies (13-15) which concluded that CPR's knowledge and experience need improvement and updating.

Only two out of $152(1.3 \%)$ dentists in this study reported that they had encountered cardiac arrest. Gonzaga et al. (10) found that $12 \%$ of Brazilian dentists referred to the occurrence of CPA outside the dental office, but only 3\% reported to having witnessed CPA in their dental office. Alkandari et al. (12) 4.3\% of Kuwaiti dentists reported having encountered cardiac arrest in dental practices. In a study to evaluate the knowledge of CPR among dentists in Iran, it was reported that though 4\% stated that they had witnessed CPA in their clinics, none of them had received any practical training (11).

In this study, while $73.7 \%$ of dentists previously had received CPR training, only $6.6 \%$ of them considered themselves adequate for CPR administration. However, the knowledge of those who received CPR training was found similar to those who did not. This indicates that CPR training information needs to be updated. Sopka et al. (16) and Laurent et al. (17) stated that near to $50 \%$ of dentists believed they could perform CPR. Gonzaga et al. (10) reported that $54 \%$ of dentists in Brazil believed they were capable of performing CPR, but although $86 \%$ had received CPR education, most had not received practical resuscitation training. Chapman (14) reported that almost two-thirds of Australian dentists claimed that they were skilled in performing CPR, while less than two-thirds had undergone practical training in CPR since graduation. Singh et al. (15) demonstrated that although 75.9\% of Indian dentists had received CPR knowledge, 56.0\% had the correct concept of skilled and only $12 \%$ had practical 
Table 2. Distribution of participants' answers to questions regarding CPR

\section{Questions}

1. What maneuver is provided by airway patency in patients without a cervical injury?

2. What maneuver is provided by airway patency in patients with cervical injury?

3. How long should the breathing and pulse be checked?

4. How is rescue breath given to infants?

5. Where is the place of application of chest compression in adults and infants in CPR?

6. What should be the ventilation rate in adult CPR?

7. What should be the compression/ ventilation ratio in adult CPR?

8. What should be the rate of chest compression in adult CPR?

9. What should be the depth of chest compression in adult CPR?

10. What medication and dose could be administered to the patient during cardiac arrest?

\section{Total}

CPR: Cardiopulmonary resuscitation, $\mathrm{n}$ : Number

*: Correct answers

\begin{tabular}{|c|c|c|}
\hline Answers & Number, $\mathbf{n}$ & Percentage, \% \\
\hline Jaw forward push-mouth opening movement & 32 & 21.1 \\
\hline Turn to head sideways movement & 12 & 7.9 \\
\hline Head back-jaw tip up movement & 108 & $71.1^{*}$ \\
\hline Head tilting backwards & 4 & 2.6 \\
\hline Jaw thrust & 38 & $25.0^{*}$ \\
\hline Tilting the head backward, lifting the chin up & 16 & 10.5 \\
\hline Immobilization & 78 & 51.3 \\
\hline I am not sure & 16 & 10.5 \\
\hline 10 seconds & 76 & $50^{*}$ \\
\hline 20 seconds & 34 & 22.4 \\
\hline 30 seconds & 36 & 23.7 \\
\hline 40 seconds & 4 & 2.6 \\
\hline I am not sure & 2 & 1.3 \\
\hline Closing the nose and mouth to mouth & 14 & 9.2 \\
\hline Mouth and nose at the same time & 106 & $69.7^{*}$ \\
\hline Mouth to nose & 22 & 14.5 \\
\hline Mouth to mouth & 2 & 1.3 \\
\hline I am not sure & 8 & 5.3 \\
\hline $\begin{array}{l}\text { The lower part of the sternum } 1 / 3 \text { in adults } \\
\text { The width of a finger under the nipple in infants }\end{array}$ & 74 & 48.7 \\
\hline $\begin{array}{l}\text { The lower part of the sternum } 1 / 3 \text { in adults } \\
\text { Inter-breast line in infants }\end{array}$ & 72 & 47.4 \\
\hline $\begin{array}{l}\text { The lower part of the sternum } 1 / 2 \text { in adults } \\
\text { The width of a finger under the nipple in infants }\end{array}$ & 2 & $1.3^{*}$ \\
\hline I am not sure & 4 & 2.6 \\
\hline 1 breath every 3 seconds (20 breaths/min) & 28 & 18.4 \\
\hline 1 breath every 4 seconds ( 15 breaths/min) & 66 & 43.4 \\
\hline 1 breath every 6 seconds ( 10 breaths/min) & 20 & $13.2^{*}$ \\
\hline 1 breath every 10 seconds ( 6 breaths/min) & 20 & 13.2 \\
\hline I am not sure & 18 & 11.8 \\
\hline $5 / 1$ & 14 & 9.2 \\
\hline $15 / 2$ & 58 & 38.2 \\
\hline $30 / 2$ & 64 & $42.1^{*}$ \\
\hline I am not sure & 16 & 10.5 \\
\hline $50-70 / \mathrm{min}$ & 42 & 27.6 \\
\hline 70-90/min & 28 & 18.4 \\
\hline $80-100 / \min$ & 28 & 18.4 \\
\hline $100-120 / \mathrm{min}$ & 42 & $27.6^{*}$ \\
\hline I am not sure & 12 & 7.9 \\
\hline $3 \mathrm{~cm}$ & 38 & 25.0 \\
\hline $5 \mathrm{~cm}$ & 98 & $64.5^{*}$ \\
\hline $7 \mathrm{~cm}$ & 4 & 2.6 \\
\hline I am not sure & 12 & 7.9 \\
\hline Atropine, 1 mg IV every 3-5 minutes & 6 & 3.9 \\
\hline Adrenaline, $1 / 2$ mg IV every 3-5 minutes & 42 & 27.6 \\
\hline Adrenaline, 1 mg IV every 3-5 minutes & 78 & $51.3^{*}$ \\
\hline Atropine, $1 / 2$ mg IV every 3-5 minutes & 12 & 7.9 \\
\hline \multirow[t]{2}{*}{ I am not sure } & 14 & 9.2 \\
\hline & 152 & 100 \\
\hline
\end{tabular}


Table 3. Knowledge, skill, and experiences of dentists related to CPR

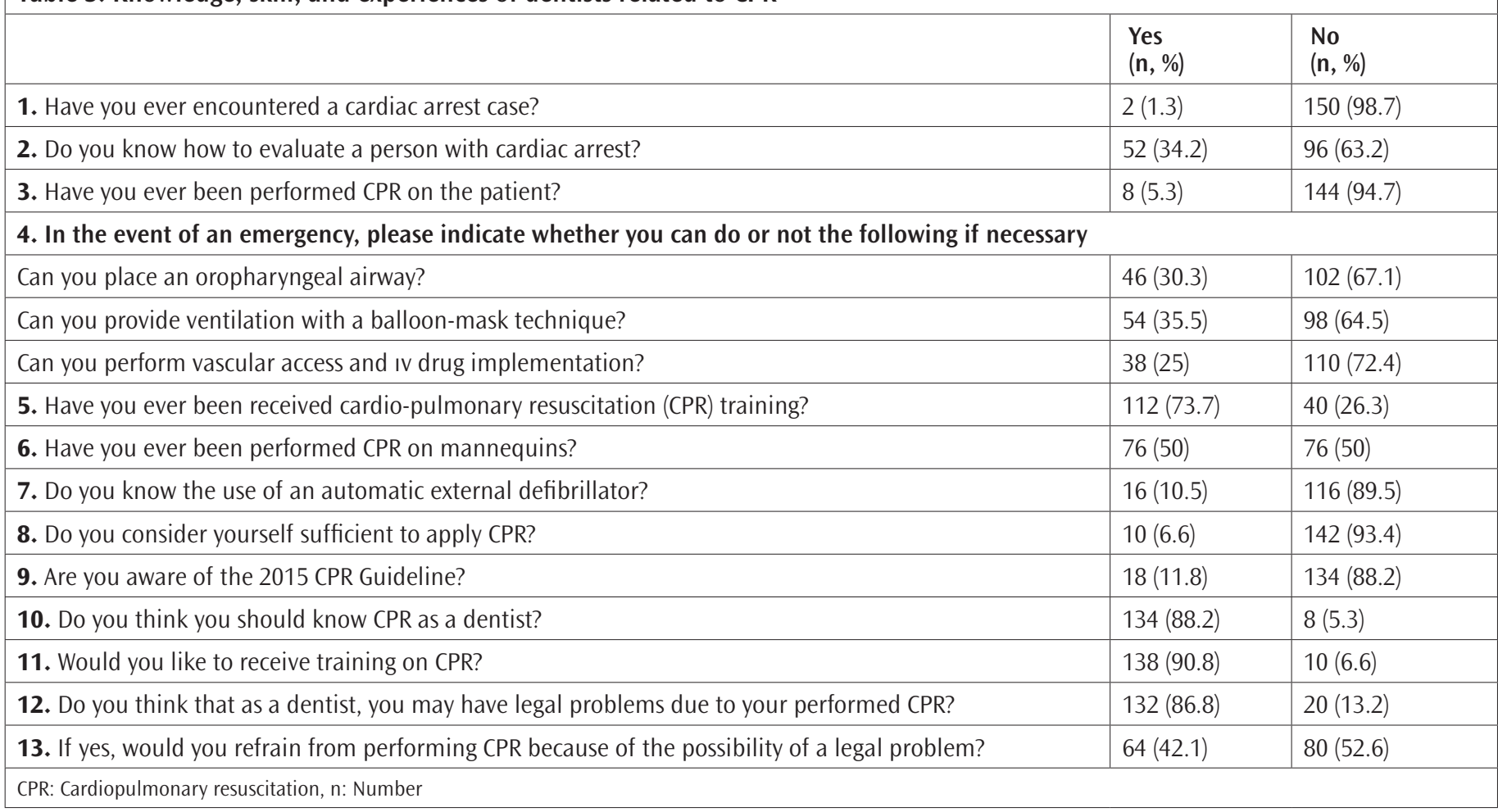

CPR training. Arsati et al. (18) reported that dentists are not fully prepared to manage medical emergencies and have inadequate training in CPR. Greenwood et al. (19) reported that $81 \%$ of participant dentists believed that they were able to manage CPA. However, participants had only one year of experience in dentistry and also they had not met any cardiac arrest during that year. Differences in the findings of the studies may be related to the different methods of research. It appears that practical application is more correct than a self-assessment questionnaire for assesment of CPR skills.

In the present study, while $88.2 \%$ of dentists stated that they should know CPR as a dentist, 90.8\% of them stated that want to get CPR training. To ensure better and safer healthcare, dentists, as a health professional, should be able to recognize CPA and must be trained to perform in high- quality CPR. In some countries, there are many opportunities for dental students to learn medical emergencies; for example; in the United States of America, the teaching of medical emergencies is compulsory in more than 95\% of dental schools and 60 hours are dedicated to training medical emergencies (20). In Iran, while before 2013, only 4 hours had been dedicated to the instruction of medical emergencies without any practical training. But now, 26 hours are dedicated to both theoretical and practical medical emergency training for dental students (13). In Turkey, emergency and first aid courses are taught to dental students in the last year of dental education in only 1 hour per week for one semester. However, theoretical courses are not enough in medical emergency training. So, this course should cover both theoretical and practical training. Recently, some universities in Turkey took this lesson to $1^{\text {st }}$ grade curriculum. It can be said that it is more appropriate to give this course in the $1^{\text {st }}$ grade. However, it should be stressed that for improving the CPR knowledge and skills of dentists, it is necessary for dentists to participate in medical emergency courses regularly after graduation.

\section{Study Limitations}

This research has some limitations. The small sample size may limit the generalization of the findings. In addition, determining only the level of theoretical knowledge without hands-on training is insufficient in evaluating the CPR skill.

\section{Conclusion}

Study findings reveal that there is insufficient knowledge of dentists on CPR in Turkey. Therefore, CPR training should be given to dentists in the country regularly. Dentists should be qualified in the use of laryngoscope, Ambu mask, oropharyngeal tube, and medications such as adrenaline. To increase the dentists' knowledge and skills to recognition and management of medical emergencies, there should be adequate training hours for both theoretical and practical courses in the undergraduate dental curriculum. We propose that dentists should update their CPR 
knowledge and skills periodically, at least every 2 years, and preferably more frequently.

\section{Ethics}

Ethics Committee Approval: This study was approved by the Ethical Committee of the Faculty of Medicine, Afyonkarahisar Health Sciences University (no: 2019/10-316, date: 04.10.2019), and was performed in full compliance with the Helsinki Declaration of the World Medical Association.

Informed Consent: Written informed consent was obtained from all participants.

Peer-review: Externally peer-reviewed.

Financial Disclosure: The author declared that this study received no financial support.

\section{References}

1. Futterman LG, Lemberg L. Cardiopulmonary resuscitation review: critical role of chest compressions. Am J Crit Care. 2005;14:81-4.

2. Cummins RO, Chamberlain DA, Abramson NS, Allen M, Baskett PJ, Becker L, et al. Recommended guidelines for uniform reporting of data from out-ofhospital cardiac arrest: the utstein style: a statement for health professionals from a task force of the American Heart Association, the European Resuscitation Council, and Heart and Stroke Foundation of Canada, and the Australian Resuscitation Council. Circulation. 1991;84:960-75.

3. Jacobs I, Nadkarni V, Bahr J, Berg RA, Billi JE, Bossaert L, et al. Cardiac arrest and cardiopulmonary resuscitation outcome reports: Update and simplification of the Utstein templates for resuscitation registries. A statement for healthcare professionals from a task force of the International Liaison Committee on Resuscitation (American Heart Association, European Resuscitation Council, Australian Resuscitation Council, New Zealand Resuscitation Council. Circulation. 2004;110:3385-97.

4. Cardiopulmonary resuscitation (CPR): First Aid Steps [Internet]. [cited 2019 December 22]. https://www.emedicinehealth.com/cardiopulmonary resuscitation_cpr/article_em.htm

5. Scapigliati A, Ristagno G, Cavaliere F. The best timing for defibrillation in shockable cardiac arrest. Minerva Anestesiol. 2013;79:92-101.

6. Fredriksson M, Herlitz J, Nichol G. Variation in outcome in studies of outof-hospital cardiac arrest: a review of studies conforming to the Utstein guidelines. Am J Emerg Med. 2003;21:276-81.
7. Handley AJ, Koster R, Monsieurs K, Perkins GD, Davies S, Bossaert L. European Resuscitation Council Guidelines for Resuscitation 2005: Section 2. Adult basic life support and use of automated external defibrillators. Resuscitation. 2010;81:1277-92.

8. Anders PL, Comeau RL, Hatton M, Neiders ME. The nature and frequency of medical emergencies among patients in a dental school setting. J Dent Educ. 2010;74:392-6

9. Hunter PL. Cardiac arrest in the dental surgery. Br Dent J. 1991;170:284

10. Gonzaga HF de S, Buso L, Jorge MA, Gonzaga LH de S, Chaves MD, Almeida OP de. Evaluation of knowledge and experience of dentists of São Paulo State, Brazil about cardiopulmonary resuscitation. Braz Dent J. 2003;14:220-2.

11. Kavari SH, Chohedri AH. Cardiopulmonary resuscitation: Knowledge and personal experience in Iranian dentists. Pak J Med Sci. 2007;23:296-7.

12. Alkandari SA, Alyahya L, Abdulwahab M. Cardiopulmonary resuscitation knowledge and attitude among general dentists in Kuwait. World J Emerg Med. 2017;8:19-24.

13. Jamalpour M, Asadi H, Zarei K. Basic life support knowledge and skills of Iranian general dental practitioners to perform cardiopulmonary resuscitation. Niger Med J. 2015;56:148-52.

14. Chapman PJ. Medical emergencies in dental practice and choice of emergency drugs and equipment: A survey of Australian dentists. Aust Dent J. 1997;42:103-8.

15. Singh K, Bhat N, Ramesh N, Sharda A, Asawa K, Agrawal A, et al. Cardiopulmonary resuscitation: Knowledge and personal experience among dentists in Udaipur, India. J Dent Sci. 2011;6:72-5.

16. Sopka S, Biermann H, Druener S, Skorning M, Knops A, Fitzner C, et al. Practical skills training influences knowledge and attitude of dental students towards emergency medical care. Eur J Dent Educ. 2012;16:179-86.

17. Laurent F, Augustin P, Nabet C, Ackers S, Zamaroczy D, Maman L. Managing a cardiac arrest: Evaluation of final-year predoctoral dental students. J Dent Educ. 2009;73:211-7.

18. Arsati F, Montalli V, Flório FM, Ramacciato J, Cunha F, Cecanho R, et al. Brazilian dentists' attitudes about medical emergencies during dental treatment. J Dent Educ. 2010;74:661-6

19. Greenwood M, Beattie A, Green R, Durham J. Aspects of training in clinical medical sciences in dentistry (human disease): Recent graduates' perspectives from a UK dental school. Eur J Dent Educ. 2013;17:114-21.

20. Clark MS, Wall BE, Tholström TC, Christensen EH, Payne BC. A twenty-year follow-up survey of medical emergency education in U.S. dental schools. J Dent Educ. 2006;70:1316-9. 